\title{
Good News...
}

\section{László Solymosi}

Published online: 5 August 2015

(C) Springer-Verlag Berlin Heidelberg 2015

In this year's third issue of Clinical Neuroradiology I am once again able to report on the pleasing development of our journal - something of a tradition now. In the middle of the year, ISI (Web of Knowledge ${ }^{\mathrm{SM}}$ ) publishes their scientific journals' ranking (Thomson Reuters Journal Citation Reports $^{\circledR}$ ) listing the latest impact factor for the previous year.

Clinical Neuroradiology is gaining evermore acceptance in the scientific world, as shown by the positive impact factor development, an important indicator of the quality of scientific journals. The list recently published by ISI confirms that our journal's impact factor is continuing to increase, with the current value for 2014 lying at $\mathbf{2 . 2 5}$.

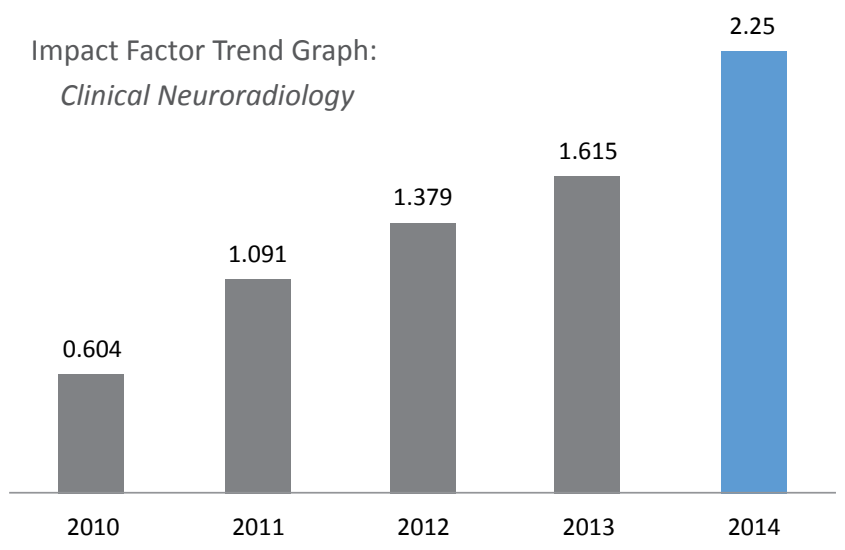

L. Solymosi $(\bowtie)$

Dept. of Neuroradiology,

Würzburg, Germany

e-mail: solymosi_1@ukw.de
Not only did the impact factor rise, but the journal's rank also improved in both categories. In the "Radiology, Nuclear Medicine \& Medical Imaging" category the journal is ranked 47 out of 125 journals in total (previous year: rank 66). In the highly competitive "Clinical Neurology" category, the journal moved up 31 places! Out of 192 journals in this category, Clinical Neuroradiology is now ranked at number 101 .

To achieve such pleasing results, we first and foremost need excellent works that are cited regularly. Therefore, our recent success is primarily down to our authors. I, like many others, regularly receive e-mail requests to submit a manuscript to certain journals. I am delighted that Clinical Neuroradiology does not have to depend on activities such as these. As the number of manuscripts submitted is continuously rising, early last year we decided to expand our Editorial Board, so that the workload can be spread between several people.

We hope that this positive trend will persist in the future. The Editorial Board and the publisher will, of course, do their best to ensure that it does.

László Solymosi

Editor-in-Chief 